\title{
Solitary Metastasis to Humerus: Unusual Presentation of Follicular Thyroid Carcinoma Diagnosed by Fine Needle Aspiration Cytology
}

\author{
Asaranti Kar1, Subhasini Naik², Pradeep K Behera3 ${ }^{3}$, Chandra S Mohapatra ${ }^{3}$, Sasmita Panda4 \\ ${ }^{1}$ Associate Professor, ${ }^{2}$ Senior Resident, ${ }^{3}$ Assistant Professor, \\ Department of Pathology, S.C.B. Medical College, Cuttack, Odisha, India. \\ ${ }^{4}$ Assistant Professor, AHRCC, Cuttack, Odisha, India.
}

\begin{abstract}
Follicular carcinoma of thyroid metastasizes to bone, clinically presenting as a large tissue swelling only, with silent primary is very rare one and is reported to be $4 \%$ of all thyroid cancers. Appendicular skeleton like humerus is a rare site of skeletal metastasis in follicular carcinoma as compared to axial skeletons. Here, we report such an unusual case of a 70 year old woman presenting with a huge swelling over left upper arm mimicking primary bone tumor both clinically and radiologically. It was diagnosed as metastatic follicular thyroid carcinoma by fine needle aspiration cytology (FNAC). Later follicular carcinoma was detected in thyroid by cytology and confirmed by histology. Patient was treated by total thyroidectomy with iodine therapy and external beam radiotherapy to bone. FNAC is a cheap, rapid, non-invasive and accurate diagnostic modality which can help in early diagnosis of such lesions helping in proper management and better prognosis.
\end{abstract}

\section{INTRODUCTION}

Follicular thyroid carcinoma (FTC) is a well differentiated thyroid tumor and is the second most common cancer after papillary carcinoma. ${ }^{1}$ Incidence of distant metastasis of FTC is 11 to $25 \%{ }^{2}$ Osseous metastasis of thyroid malignancy is considered rare and is $15.2 \%$ in FTC. They are usually multiple and solitary metastasis is extremely rare. Commonly they metastasize to shoulder girdle, sternum, skull, and iliac bones and very rarely to appendicular skeleton. Usually osseous metastasis of FTC is detected after diagnosis of primary lesion but infrequently they can be the only presenting symptom and often confused with primary bone tumors. Metastatic FTC have relatively better prognosis as compared with other forms of metastatic malignancies, if they are diagnosed early. We report one similar case of a 70-year-old woman, in whom solitary bone metastasis to humerus was the only presenting symptom of FTC confused with primary bone tumor both clinically and radiologically and was diagnosed by fine needle aspiration cytology (FNAC).

\section{CASE REPORT}

A 70-year-old woman presented with chief complaint of a progressively increasing swelling over left upper arm (Fig. 1A) for 8 months. There was mild pain with restriction of movements. During examination, she was of thin body built and had gross weight loss and loss of appetite for last two months. On local
Key Words: Follicular Carcinoma Thyroid, FNAC, Humerus, Metastasis.

\section{*Correspondence to:}

Dr. Asaranti Kar,

Qrs. No.-JO/1,

S.C.B.Medical College,

Cuttack, Odisha, India.

\section{Article History:}

Received: 24-08-2016, Revised: 31-08-2016, Accepted: 17-09-2016

\begin{tabular}{|l|c|}
\hline \multicolumn{2}{|c|}{ Access this article online } \\
\hline $\begin{array}{l}\text { Website: } \\
\text { www.ijmrp.com }\end{array}$ & Quick Response code \\
\hline DOI: & \\
10.21276/ijmrp.2016.2.5.046 & \\
\hline
\end{tabular}

examination, she had a huge swelling occupying middle one third of left upper arm with glistening erythematous surface, firm to hard in consistency, mildly tender with dilated cutaneous veins on surface. She did not have any regional lymphadenopathy. Laboratory investigations revealed raised ESR. There was no other relevant medical or family history. Radiograph of left arm AP and lateral view showed a multiloculated osteolytic lesion separated by few thinned out remaining bony trabeculae measuring $6 \times 5 \mathrm{~cm}$ in the diaphysis of left humerus. (Fig. 2) Lesion was expansile, ill-defined and destructive with permeative margins, and was associated with large soft tissue swelling without any evidence of calcification.

Basing on these radiographic findings of a large destructive bone tumor with a prominent soft tissue component, a provisional radiological diagnosis of primary malignant bone tumor probably osteosarcoma or fibrosarcoma was proferred.

FNAC was done from the humeral mass. Cytosmears were highly cellular. Mostly cell were arranged in clusters, small repetitive acini and singly. Cells have monotonous enlarged, hyper chromatic nuclei with mild anisonucleosis and scanty to moderate amount of pale blue-grey cytoplasm with pink periphery (Fig. 3A), suggesting a metastatic adenocarcinoma.

After this finding, detail physical examination of the patient was done for the search of primary site. Surprisingly we got no relevant 
finding except two small inconspicuous nodules of size $1 \mathrm{~cm}$ each in right lobe of thyroid (Fig. 1B). So, FNAC was done from the thyroid nodules. Cytosmear of first nodule showed scattered thyroid follicular cells admixed with cyst macrophages in a fluid background suggestive of cystic degeneration. Second nodule showed cellular smears. Follicular cells in repetitive follicles and some were showing nuclear pleomorphism with minimal colloid in a haemorrhagic back ground suggestive of follicular neoplasm

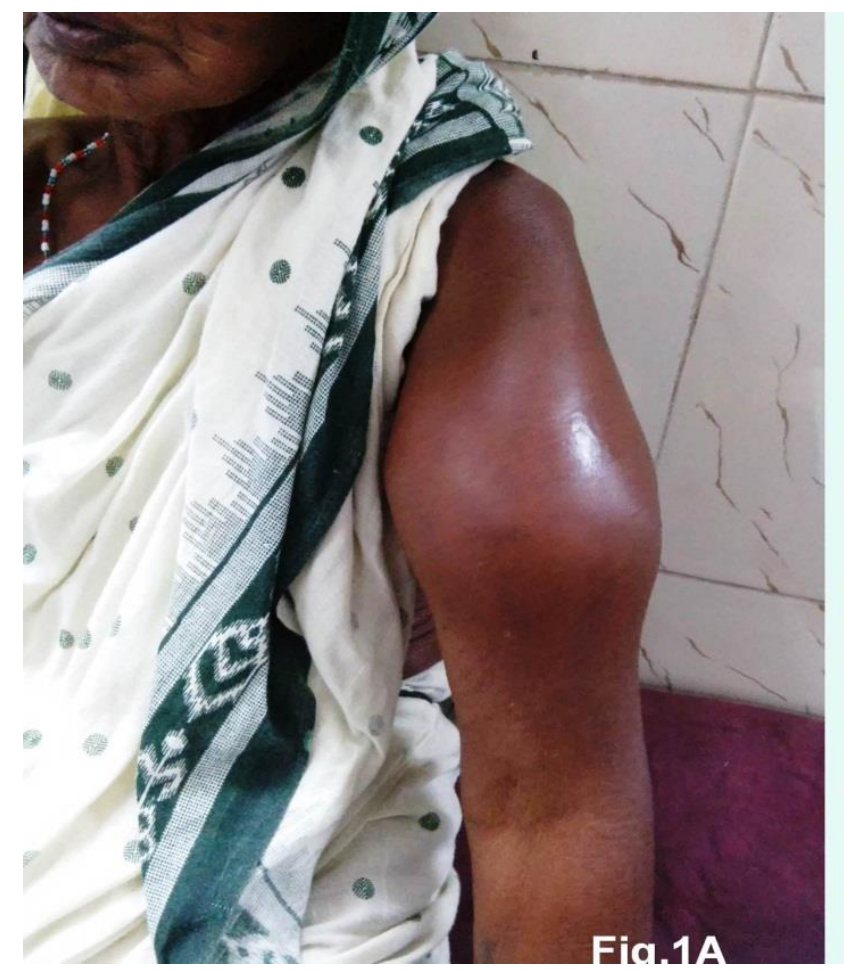

(Fig.3B). Cellular architecture and morphology of thyroid aspiration corresponds to that of cells found in the bony aspirate. So it was diagnosed as a case of follicular carcinoma of thyroid that metastasized to humerus. Later total thyroidectomy was done. FTC was confirmed from histological examination (Fig. 4 $A, B)$. Histosection of the thyroid tumor showed follicles of varying sizes with small areas of solid growth pattern and having extensive capsular and vascular tumoral invasion.

Fig. 1A: Large swelling of left upper arm, B: Inconspicuous nodule in thyroid of the patient

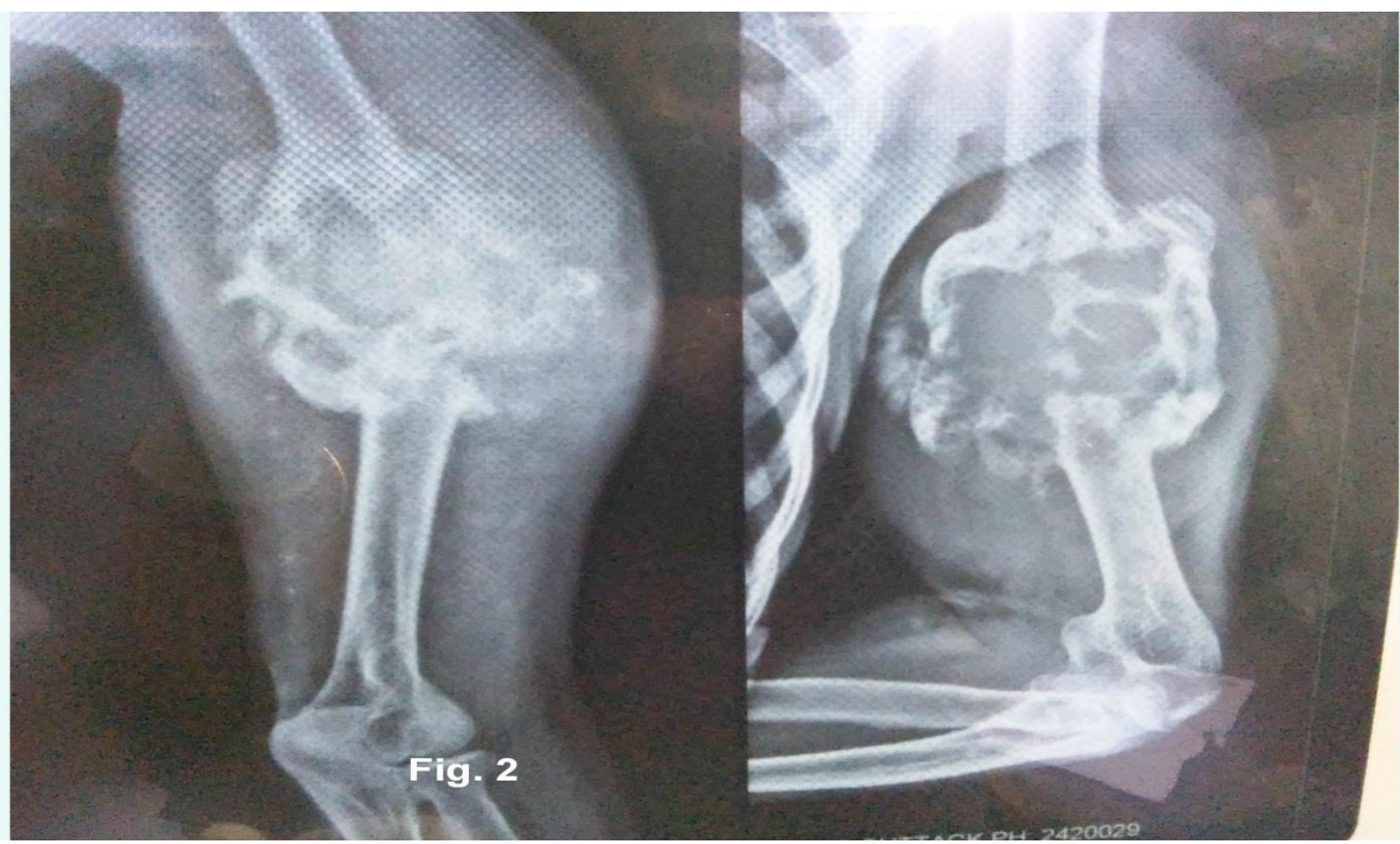

Fig 2: Radiograph left upper arm AP and Lateral view show an expansile destructive lesion in the diaphysis with soft tissue swelling. 

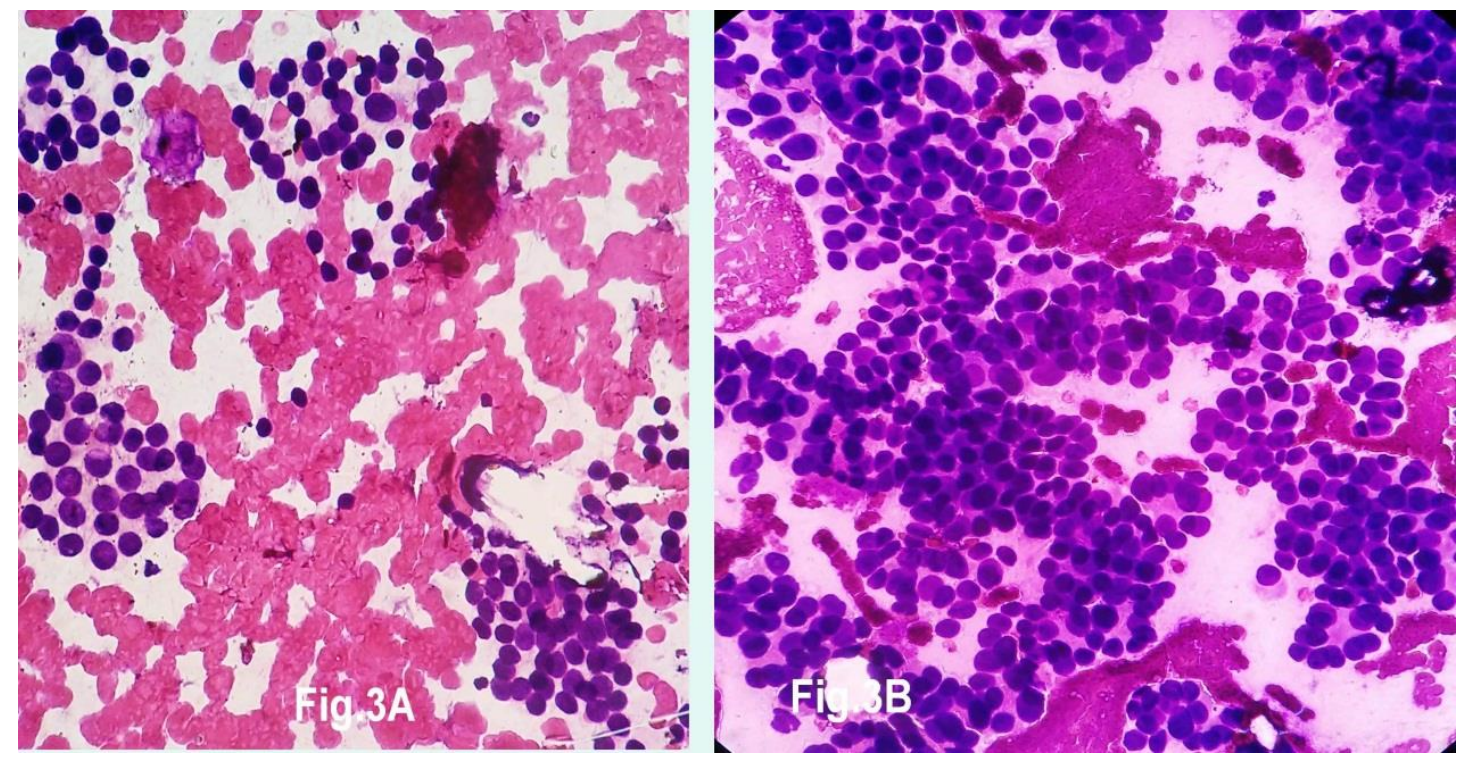

Fig 3A: Clusters of follicular carcinomatous cells over hemorrhagic background in bone aspirate.

B: Cellular cytosmear from thyroid aspirate showing similar cells. H\&E stain $\mathrm{x} 400$.
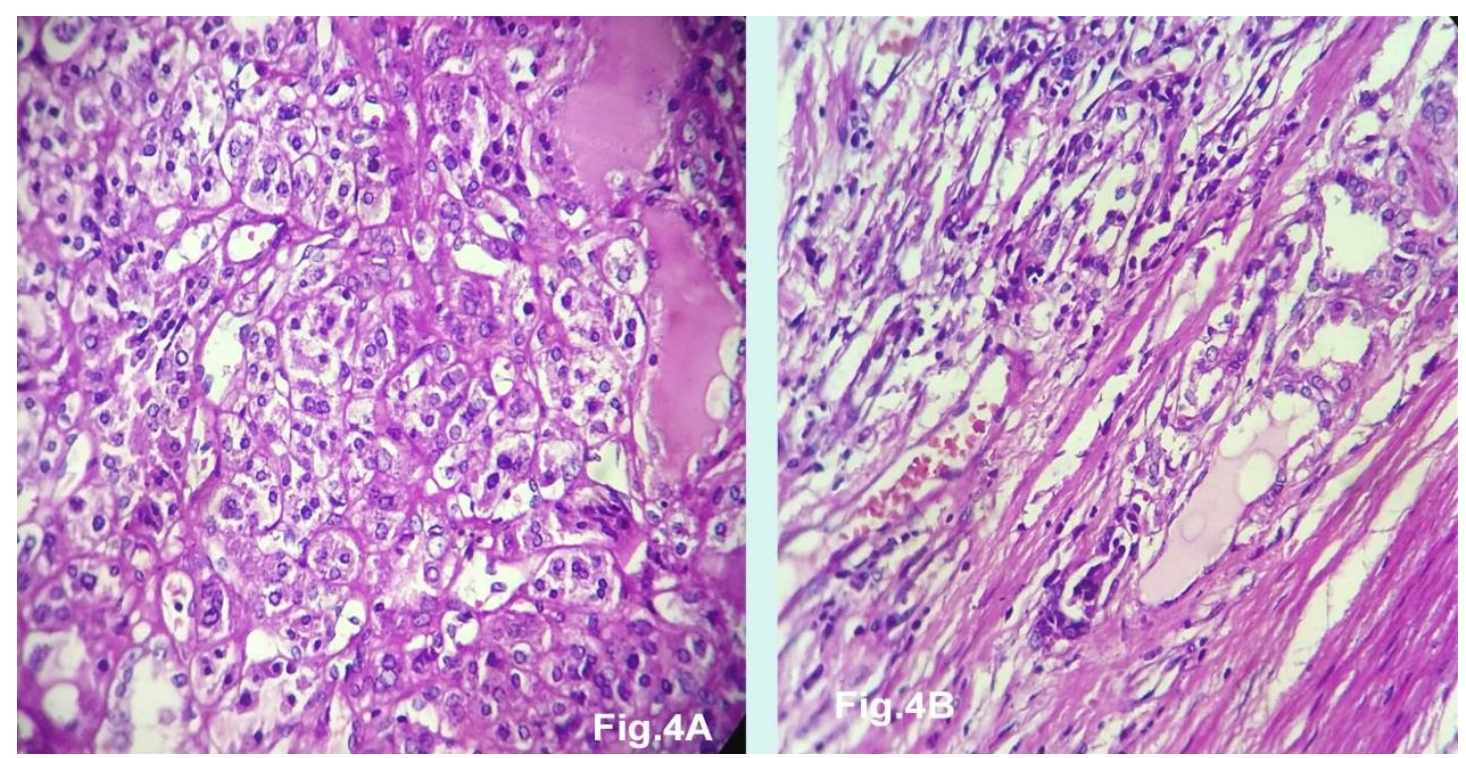

Fig 4 A \& B: Histopathology of follicullar carcinoma of thyroid. H\&E stain $x 400$.

\section{DISCUSSION}

Thyroid cancer is the most common tumor of the endocrine system; accounting for $1 \%$ of the malignancies with incidence rate of about 3.7 to 4 per 100.000 populations. ${ }^{1}$ Among all thyroid cancers follicular thyroid carcinoma comprises 10-15\%.1 Papillary and follicular variants are well differentiated, highly treatable and usually have a good prognosis but FTC is more aggressive and occurs in a slightly older age than papillary variant. $1-3 \%$ of thyroid cancer can develop distant metastasis. It is about $10 \%$ in papillary carcinoma and up to $25 \%$ of those with follicular carcinoma. Follicular thyroid carcinoma metastasizes by the haematogenous route, commonly to the lung, bone, brain, and liver and lymph nodes. Bone metastasis in well-differentiated FTC is $7 \%$ to $28 \%$, while in papillary carcinoma it is $1.4 \%$ to $7 \%{ }^{3}$

Common sites of bone metastasis of FTC are axial skeletons, and rarely appendicular skeletons. Vertebrae are the commonest site followed by ribs, pelvic bones, skull and rarely femur and humerus. Again In axial skeletons incidence decreases from proximal to distal part of the bone. But in the above case, the middle part of the humerus was involved, which is unusual for bone metastasis and with large smooth soft tissue swelling it is more suggestive of primary bone tumor. Metastasis in thyroid carcinoma are often multiple and rarely patients with FTC initially presents to the clinicians with a solitary distant metastasis the primary being silent. Shaha et al reported that only $4 \%$ patients with thyroid cancer presented initially with a distant metastasis which was encountered in the present case. ${ }^{4}$

Tumors of bone are difficult to diagnose because of their rarity and unusual presentation. Bone metastasis can be purely lytic, blastic, and mixed. Primaries for lytic lesions are liver, breast and thyroid carcinoma. Osteolysis and blow out appearances of the bone are usually associated with secondaries from thyroid. Lytic metastasis may remain occult in conventional radiographs until it has completely destroyed bone trabeculae and reached 2-3 cms diameter in size. ${ }^{5}$ Distant solitary metastasis in thyroid carcinoma is well documented in many studies. Few reports are published where FTC initially presented with solitary metastasis in skull, pelvis, soft tissue and skin. Khan MN et al. described spinal 
metastasis as the initial presentation in a case of FTC and suggested metastatic thyroid carcinoma should be considered in the differential diagnosis of every patient with new onset spinal cord compression. ${ }^{5}$ But, solitary metastasis to humerus is an unusual presentation of FTC which was diagnosed by FNAC in the present case. Cytosmears from the arm swelling and silent thyroid nodule exhibit similar cellular architecture and morphology that concludes follicular carcinoma of thyroid metastasizing to diaphysis of humerus. Cytodiagnosis was confirmed by histological diagnosis of total thyroidectomy specimen. Mittal et al. reported cytodiagnostic accuracy was $100 \%$, in metastatic bone cancers including metastasis from thyroid. FNA can yield diagnostic material from metastatic lesions. It can be of great help in differentiating between primary and secondary bone tumors according to Mittal et al. ${ }^{6}$

Most importantly metastatic disease of FTC decreases the quality of life, and shortens the patients' survival and is the primary cause of death. However, with appropriate early initial evaluation and management, good survival rate is possible, which happened in the present case. Proye et al. demonstrated that follicular carcinoma is usually less life threatening, and that early diagnosis and appropriate treatment for distant metastases can significantly prolong the life span and improve life quality. ${ }^{7}$ The methods used more than 15 years ago for diagnosis and treatment differ, however, from the present management. A more recent study shows that survival drops to $14 \%$ for patients older than 40 years with macronodular lung metastases or multiple bone metastases (Durante et al. 2006). ${ }^{8}$ If managed properly the survival rate can increase upto $43 \%{ }^{4}$

In the present case, total thyroidectomy was done and in addition to 131 l treatment, external beam radiation therapy (EBRT) was given for bone metastases. The patient responded well to the treatment and doing well. Accurate staging for appropriate followup allows early detection and improves treatment results. Furthermore, gene expression profiling could detect evidence on tumor aggressive characteristics and propensity to metastasize. This profiling and several staining techniques were described by Kebebew et al in 2007 on FNAB specimens also. ${ }^{9}$

To conclude, this was an unusual case of humerus metastasis which was the only initial presentation of the patient, mimicking a primary tumor of the bone and was diagnosed as follicular thyroid carcinoma from fine needle aspiration cytology of both bone swelling and a small thyroid nodule. So, when an elderly female presents with a large solitary slow growing osteolytic destructive lesion in humerus, apart from primary bone tumors, we must not forget about metastatic FTC. Early diagnosis is foremost for better prognosis.

\section{REFERENCES}

1. Tai P, Moud RF, Prysyazhnyuk AY, Gristchenko VG, Obodovsky IA. Descriptive epidemiology of thyroid carcinoma. Current Oncology 2003;10: 54-65.

2. Sevinc A, Buyukberber S, Sari R, Baysal T, Mizrak B. Follicular thyroid cancer presenting initially with soft tissue metastasis. Jpn J Clin Oncol 2000; 30: 27-9.

3. Varshney S, Pant HC. Unusual bone metastasis from follicular carcinoma thyroid:presenting as a primary bone malignancy. Int J Cancer Ther Oncol 2014; 2:020411.

4. Shaha AR, Shah JP, Loree TR. Differentiated thyroid cancer presenting initially with distant metastasis. Am J Surg. 1997; 174: 474-6.

5. Khan MN, Sharfuzzaman AMSM. Mostafa MG. Spinal cord compression as initial presentation of metastatic occult follicular thyroid carcinoma. J Neurosci Rural Pract. 2014; 5: 155-59

6. Mittal RL, Mittal RK, Ashok G. Cytodiagnosis of lesions of bones and joints by means of fine needle aspiration. Ind J Surg 1992; $54: 17-20$.

7. Proye CA, Dromer DH, Carnaille BM, Gontier AJ, Goropoulos $A$, et al. Is it still worthwhile to treat bone metastases from differentiated thyroid carcinoma with radioactive iodine? World $\mathrm{J}$ Surg 1992; 16: 640-45.

8. Durante C, Haddy N, Baudin E, Leboulleux S, Hartl D, Travagli JP et al. Long-term outcome of 444 patients with distant metastases from papillary and follicular thyroid carcinoma: benefits and limits of radioiodine therapy. Journal of Clinical Endocrinology and Metabolism 2006; 91:2892-99.

9. Kebebew E, Weng J, Bauer J, Ranvier G, Clark OH, Duh QY et al. The prevalence and prognostic value of BRAF mutation in thyroid cancer. Annals of Surgery 2007; 246:466-70.

\section{Source of Support: Nil. Conflict of Interest: None Declared.}

Copyright: (c) the author(s) and publisher. IJMRP is an official publication of Ibn Sina Academy of Medieval Medicine \& Sciences, registered in 2001 under Indian Trusts Act, 1882.

This is an open access article distributed under the terms of the Creative Commons Attribution Non-commercial License, which permits unrestricted non-commercial use, distribution, and reproduction in any medium, provided the original work is properly cited.

Cite this article as: Asaranti Kar, Subhasini Naik, Pradeep K Behera, Chandra S Mohapatra, Sasmita Panda. Solitary Metastasis to Humerus: Unusual Presentation of Follicular Thyroid Carcinoma Diagnosed by Fine Needle Aspiration Cytology. Int J Med Res Prof. 2016; 2(5):212-15. 